\title{
A clausura feminina em A Corda de Prata, de Lúcio Cardoso, e Mathilda, de Mary Shelley
}

\author{
Female clausure in The Silver Rope, by Lúcio Cardoso, \\ and Mathilda, by Mary Shelley
}

\author{
Leonardo Ramos Botelho Gomes ${ }^{1}$ \\ Fernando Monteiro de Barros Jr. ${ }^{2}$
}

\author{
Recebido em: 30/07/2020 \\ Aprovado em: 20/10/2020 \\ Publicado em: 20/12/2020
}

RESUMO: O presente trabalho propõe uma análise gótica do texto dramático $A$ corda de prata (1947), do escritor mineiro Lúcio Cardoso, no qual problematiza-se a família burguesa, a condição da mulher no espaço doméstico e a desintegração da mesma neste ambiente repressor, cujo resultado culminará em loucura e crime. Compreendendo e realçando a clausura como espaço de manifestação vampírica, pretende-se apontar o vampirismo sofrido pela personagem feminina como condição viável ao rompimento com uma dada repressão social. Ao mesmo tempo, estabelece-se um diálogo com a novela Mathilda (1820), da escritora inglesa Mary Shelley, a fim de identificar similaridades temáticas e de composição de personagens e espaços da tradição literária gótica inglesa que figurarão, a seu modo, no texto cardosiano. A fim de embasar as questões elencadas, recorre-se às considerações de Maria da Conceição Monteiro, bem como às de Jaime Ginzburg com relação à violência, Christopher Lasch no que tange a domesticidade burguesa, e a Claude Lecouteux e Mario Praz acerca de questões ligadas ao gótico e ao mito vampírico.

Palavras Chave: Gótico; Vampirismo; Lúcio Cardoso; Mary Shelley.

ABSTRACT: This work proposes a Gothic analysis of the dramaThe silver rope (1947), by Lúcio Cardoso, which problematizes the conditions of women and the bourgeois family in the domestic space, her disintegration in this repressive environment, which will lead to madness and crime. Understanding and highlighting enclosure as a space for vampiric manifestation, we intend to point out the vampirism perpetrated by the female character as a viable condition to break down with given social repression. At the same time, a parallel can be established with the novel Mathilda (1820), by Mary Shelley, in which we are able to identify similarities both thematic as well as in the composition of characters and spaces of the English Gothic literary tradition that will appear, in their own way, in the Cardosian text. Supporting our questions are the considerations by Maria da Conceição Monteiro, as well as those by Jaime Ginzburg regarding violence, by Christopher Lasch regarding bourgeois domesticity, and by Claude Lecouteux and Mario Praz about issues linked to the gothic and the vampiric myth.

Keywords: Gothic; Vampirism; Lúcio Cardoso; Mary Shelley.

1. Graduado em Letras - Língua Portuguesa e Literaturas. Mestrando em Estudos Literários. Integra o grupo Estudos do Gótico (UERJ) e desenvolve pesquisa no projeto Literatura Gótica Brasileira.ORCID: 0000-0002-5452-6505 E-mail: leonardorbgomes@gmail.com

2. Doutor em Letras (Letras Vernáculas - Literatura Brasileira) pela Universidade Federal do Rio de Janeiro (2002). Desenvolve os projetos de pesquisa Literatura Gótica Brasileira, O Decadentismo na Poesia Brasileira 1880-1920, e Modernismos Crepusculares, dentro da linha de pesquisa Literatura, Teoria e História. Integra o GT Vertentes do Insólito Ficcional (ANPOLL). Professor Associado de Literatura Brasileira da Faculdade de Formação de Professores da Universidade do Estado do Rio de Janeiro. ORCID: 0000-0001-5677-6834 E-mail: fernandobarros.letras@gmail.com 


\section{INTRODUÇÃO}

O título deste trabalho talvez provoque um estranhamento inicial no leitor; o que justificaria contundentemente uma aproximação entre Mary Shelley e Lúcio Cardoso? Enquanto aquela inscreve sua produção na tradição britânica novecentista, este publica em terras brasileiras, no auge da ficção regionalista. Acreditamos que Frankenstein (1818) e Crônica da casa assassinada (1959) sejam cartões de visita da escritora e do escritor em questão, obras que certamente chancelam o projeto literário dos mesmos. Para este trabalho, entretanto, optamos por visitar duas produções de menor projeção entre o público brasileiro: Mathilda, novela concluída em 1820, mas publicada apenas em 1959, e A corda de prata, texto dramático de Lúcio Cardoso datado de 1947, vindo à publicação apenas em 2006.

Se goticismos estão presentes nas construções ficcionais citadas não só nos interessa evidenciá-los, sobretudo no que tange ao arquétipo vampírico ao qual os dois recorrem, mas explorar também a condição de clausura do desejo a qual as personagens estão submetidas, o que questiona a segurança e estabilidade esperada da vida doméstica. Partiremos da percepção das relações intrafamiliares e a ruína destas enquanto possível tônica do gótico literário, que contesta a ordem social vigente, seja no que tange à tirania e poderes de ordem política, seja nas questões de sexualidade e costumes, utilizando, para tal, as convenções narrativas próprias do gênero. Lembramos que, como considerado no estudo de Peter Gay acerca da experiência burguesa,

desde tempos imemoriais, a família havia sido o centro organizador de paixões desenfreadas, o núcleo de preservação de estimadas crenças, o instrumento preferido de socialização. Era a família que estabelecera as regras, garantira a obediência aos tabus e dirigira as energias eróticas. No século XIX a família de classe média era a responsável por tudo isso (GAY, 1988, p. 303).

É a esfera privada familiar que será o motor das tramas a serem analisadas; nas duas produções, o lar burguês nos é apresentado enquanto espaço de inquietação, passível de jogos de poder entrelaçados pelo teor erótico das relações íntimas, que findam em expressões de violência. Deste modo, Mary Shelley contesta o culto à domesticidade próprio de seu século, ao tempo em que Lúcio Cardoso realiza o mesmo movimento em relação à instituição matrimonial regida pelo patriarcado. As personagens femininas das obras partilham desta mesma regência: Mathilda está sob o poder do pai 
GOMES, L.R.B.; , JUNIOR,F.B.M.

assim como Gina está sob o poder do marido. Enquanto na trama de Shelley a família extrapola limites morais pelas ações do pai, no enredo de Cardoso tal transgressão se darápela esposa. Forte vínculo é estabelecido nesta ruptura: o vampirismo e a clausura.

\section{O gótico nas relações intrafamiliares: clausura e vampirismo}

Interessa-nos, no decorrer do presente trabalho, identificar as particularidades de cada obra no questionamento de um dado poder vigente, bem como os campos temáticos aos quais as mesmas se associam. Para empreender este estudo nos aproximamos do casal principal Gina e Renato, do texto dramático de Lúcio Cardoso, assim como de Mathilda e seu pai, do texto de Mary Shelley, pares que permitem, dada a dinâmica de tratamento que se desenvolve entre os mesmos, que reflitamos sobre a ocorrência do monstruoso no privado. A manifestação da violência no espaço doméstico parece questão recorrente no gótico, já que não são raras, na tradição literária, produções que tematizam relações intimas e a perversidade nestas, por meio do vampirismo ou não. (Pensemos, por exemplo, em Catherine Earnshaw e Heathcliff, o jovem de Corinto e sua noiva, Romuald e Clarimonde, respectivamente criações de Emily Brontë, Goethe e Théophile Gautier).

A articulação de tais campos nos textos aqui selecionados será apresentada de modo intercalado. O texto dramático $A$ Corda de Prata é estruturado em três atos e composto por cinco personagens, a saber: Gina, Renato, Júlia, Dr. Vitor e a Mulher de Preto. Detemo-nos, prioritariamente, em Gina e seu marido, Renato, afinal, é a relação conturbada do casal que manifesta a violência no espaço doméstico.

A rubrica do Primeiro Ato impõe à cena uma delimitação que nos interessa: a casa burguesa. O gótico se define, em sua tradição literária, na fronteira da cultura burguesa uma vez que "ao encenar dilemas sociais e psicológicos, tanto confronta a burguesia em suas limitações como the oferece, dialeticamente, modos de transcendência imaginária", como ressaltado no estudo da professora Maria Conceição Monteiro (VASCONCELOS apud MONTEIRO, 2004, p. 12).

Inicialmente o leitor é apresentado a Renato, marido de Gina, que com um grito e a mão ferida, busca auxílio em Júlia, a empregada que conhece a patroa desde criança. A partir destes personagens se tece um retrato de Gina, sobretudo de seu temperamento, sendo este um dos primeiros indícios de associação entre Gina e o mito de Lilith, a primeira mulher criada na tradição cabalística, que após um desentendimento com Adão a respeito da igualdade entre os dois, foge do Éden e, desde então, se torna a 
GOMES, L.R.B.; , JUNIOR,F.B.M.

"perturbadora do leito conjugal" (CHEVALIER, 1996, p. 548). A representação de Lilith prenuncia, por sua vez, a imagem das lâmias, seres que "são amorosas e desejam os prazeres do amor, mas sobretudo a carne dos humanos, e os seduzem proporcionando-lhes prazeres amorosos, os mesmos que elas querem para saciar-se" (LECOUTEUX, 2005, p. 83), que, por sua vez, se desdobra na vampira.

Os conflitos do casal, em resumo, são oriundos da inadaptação da personagem feminina às imposições do casamento. Um dos episódios que exemplifica tal afirmação se dá no momento em que Gina destrata o Dr. Vitor, médico que realiza a análise clínica da personagem. Tal relato é feito por Renato à empregada, Júlia: "Apenas disse a ela: Gina, é preciso que você mude o seu modo de proceder [...] não sei o que fiz, dei um murro na mesa [...] Disse-lhe: 'você precisa compreender que se casou comigo e que portanto deve aceitar certas obrigações!' Ela ficou muito pálida e não respondeu coisa alguma" (CARDOSO, 2006, p. 149). Em uma discussão acalorada, do casal, Renato reivindica: "Afinal, Gina, sou seu marido!" (CARDOSO, 2006, p. 161). É com amargura que Gina responde: "Sim, casamo-nos. Isto quer dizer que pertencemos um ao outro, de corpo e alma. Não é o que a Igreja diz? Mas engana-se, Renato, eu não acredito nestas tolices e sei muito bem que não temos o mesmo pensamento e desejamos coisas diferentes" (CARDOSO, 2006, p. 161). O cotidiano repressor no qual Gina está inserida manifesta-se na fala da mesma, que declara: "não tenho um só minuto de sossego desde que pisei nesta casa" (CARDOSO, 2006, p. 161).

Em um primeiro momento do texto parece-nos tendencioso conceber a personagem Gina como a parte que prejudica o bem-estar dos parceiros, afinal, somos apresentados à mesma pela perspectiva do marido, do médico e da empregada. Entretanto, uma leitura atenta aos pequenos incidentes relatados pelo marido permite-nos pensar que por meio deste se dá um sutil abuso psicológico, amparado por sua posição de homem e marido, posição que, culturalmente, Ihe conferiria certos 'direitos'. Temos, assim, um marido coercitivo a partir da legitimidade que a instituição matrimonial, na perspectiva patriarcal de sociedade, confere ao cônjuge com relação à mulher, poder, aqui, exercido por meio da manipulação psicológica que fundamenta a atitude de domínio.

Mathilda, por sua vez, é uma novela da escritora inglesa Mary Shelley concluída em 1820, mas publicada apenas em 1959. O século de distância é justificado pela temática da mesma, que apresenta como um tema central um suposto incesto entre pai e filha. Como característico do gótico inglês, Mathilda é uma jovem órfã, que perdera a mãe 
GOMES, L.R.B.; , JUNIOR,F.B.M.

no parto. O pai, por sua vez, deixa-a com uma tia distante e percorre o mundo, regressando ao lar apenas quando a menina já está com dezesseis anos.

A novela, narrada em primeira pessoa e de modo epistolar, é um autoexame da personagem principal que, de modo distinto das narrativas tradicionais proeminentes do cânone literário gótico, sobretudo do período setecentista (na linhagem de Horace Walpole, Matthew Lewis, Ann Radcliffe...), evidencia o discurso da personagem feminina, assim como o comportamento da mesma desafia o vilão gótico, aqui evocado na figura paterna. De certo modo, Mary Shelley reinventa o arquétipo da donzela gótica ao construir uma narrativa na qual, apesar das perseguições e paixões a ela direcionadas, a personagem assume o controle discursivo e é ativa no conflito familiar, inquirindo e questionando o pai quanto ao comportamento deste, algo pouco típico na tradição literária gótica inglesa, na qual a heroína é geralmente narrada e não narradora.

O relacionamento entre o pai, não nomeado, e a filha, que intitula a novela, é perturbado pelas paixões violentas que acometem o pai, que enxerga a filha como a esposa falecida. A relação apresenta traços de abuso psicológico por parte do mesmo, que manifesta alterações bruscas de humor, instabilidade emocional, raiva e dureza, posturas, por fim, que inquietam Mathilda, aflita pela incompreensão do que se passa com seu pai. Tal convivência é envolta pela dubiedade de sentimentos; acerca do pai, Mathilda admite: "havia uma estranheza que me atraía e encantava" (SHELLEY, 2015, p. 37).

A atmosfera gótica está presente nos textos em sua quase totalidade. $O$ ponto que une as personagens femininas das duas obras é a clausura. O enclausuramento no texto cardosiano é realçado a partir da representação do quarto do casal, espaço no qual Gina se mantém reclusa e passa a maior parte do dia: "as paredes são de cor cinza escura e não possuem nenhuma janela. Uma única porta se comunica com a parte inferior da casa, e é uma porta gradeada, de varões grossos como os de uma prisão. 0 quarto não possui outros móveis" (CARDOSO, 2006, p. 167). A composição deste quarto, o qual a personagem Renato revela ser o mais abafado da casa, alude não só à clausura da personagem, mas parece resgatar a atmosfera tão presente na tradição literária gótica inglesa, do confinamento do castelo e, o que parece mais propício aqui, do convento.

A novela de Shelley, por sua vez, como próprio das produções de sua época, se desenrola em regiões montanhosas, entre campinas e charnecas, mansões e passeios em bosques, que evocam aspectos do sublime. A personagem feminina também é apresentada por meio da introspecção e do retiro, mas sua situação solitária e de clausura só é intensificada após um episódio traumático com seu pai. 
GOMES, L.R.B.; , JUNIOR,F.B.M.

Citando Os mistérios de Udolpho (1794), romance de Ann Radcliffe, Conceição Monteiro aponta a constituição do castelo como "um espaço de sedução e medo", além da "personificação ameaçadora do poder masculino" (2004, p. 40), considerações interessantes à reflexão do espaço doméstico da personagem cardosiana Gina:

o castelo de Udolpho constitui um bom exemplo de questionamento pela narrativa gótica da soberania das estruturas de poder. Isolado, o castelo torna-se um espaço para o horror, o estranho, mostrando-se uma versão grotesca do lar da classe média inglesa, onde as mulheres devem agir como anjos e sentirem-se, também, num espaço protegido. Vê-se, assim, que toda a contextualização do castelo ridiculariza a ideologia do espaço da mulher (MONTEIRO, 2004, p. 43).

O romance de Bram Stoker, Drácula, datado de 1897, não só mitifica e solidifica o castelo enquanto topos gótico, o que já se estabelecera no considerado romance fundador do gótico O castelo de Otranto (1764), de Horace Walpole, como também remete à clausura do vampiro, em nível metafórico, mas também em sua relação espacial. É pelo diário de Jonathan Harker que se toma conhecimento das três mulheres que habitam o castelo da Transilvânia. A desobediência a uma das recomendações do Conde (de não dormir em qualquer parte do castelo, senão no próprio aposento) é o que permite o encontro com as mesmas; Harker é tomado pela sonolência e, em um primeiro momento, apresenta dúvidas se os acontecimentos que seguiram foram reais ou sonhos. Apesar da luz brilhante da lua, as três damas que apareceram no aposento não projetavam sombras no chão. Jonathan sente medo frente às damas de "dentes brancos e brilhantes que cintilavam como pérolas" (STOKER, 2011, p. 54), vê-se em uma oscilação entre "desconforto, desejo e ao mesmo tempo um terrível temor" (STOKER, 2011, p. 54).

Entre sussurros, as damas decidem quem tem o "direito de começar", a qual uma acrescenta: "ele é jovem e forte, há beijos para todas nós" (STOKER, 2011, p. 55). Sob o hálito da jovem, Harker sente um hálito doce e repugnante, algo como sangue e observa de olhos entreabertos os lábios que pareciam se deslocar ao seu pescoço. No movimento da jovem "havia uma voluptuosidade deliberada que era ao mesmo tempo excitante e repulsiva" (STOKER, 2011, p. 55), maneira com a qual tocou com os dentes afiados 0 pescoço de Jonathan, que esperava os próximos passos em um "êxtase languido".

A cena só é interrompida pela presença do conde, que furioso as afasta, dizendo quase em murmúrio: "como ousam tocá-lo? Como ousam pôr os olhos nele, quando eu as proibi? Pra trás, todas vocês. Este homem pertence a mim!" (STOKER, 2011, p. 56). Pela atitude, uma delas questiona a impossibilidade de amar que lhe era própria, afirmação a qual o conde retruca: "não, também eu sou capaz de amar" (STOKER, 2011, p. 57). A 
GOMES, L.R.B.; , JUNIOR,F.B.M.

condição vampírica parece atrelada ao amor, sobretudo à impossibilidade para tal. $\mathrm{O}$ conde as dispensa com um saco no qual dentro algo se mexe, como uma criança sufocada, e as damas somem de modo inexplicável, como nos raios do luar, cenas que provocam em Jonathan a perda dos sentidos.

A atitude voluptuosa das mulheres em relação a Jonathan, a atmosfera noturna e, portanto, lunar, bem como o ambiente de delírio são todos elementos que rodeiam a relação de Renato e Gina no texto cardosiano. A atração e repulsa de Jonathan com relação às vampiras também é outra sensação compartilhada por aqueles que são vampirizados, como se dá em Renato frente a Gina e na relação de Mathilda com seu pai. Mas não só as vampiras vivem em condição de claustro, como o próprio conde, que expressa nos trechos destacados acima o desejo por Jonathan, como também a condenação de estar em um corpo impossibilitado para o amor, sede da qual também partilha Gina e o pai de Mathilda.

O convento, por sua vez, será um espaço utilizado não só em O monge (1796), de Matthew Lewis, mas também nos romances de Ann Radcliffe. Refletindo acerca de tal espaço no romance radcliffeano, Maria da Conceição Monteiro afirma: "o convento torna-se, assim, locus de repressão sexual, ou melhor, de esconderijo da sexualidade, sendo ao mesmo tempo, paradoxalmente, o espaço onde o sexo é alimentado" (MONTEIRO, 2004, p. 60). Ainda segundo a mesma, o convento seria integrado à narrativa como "espaço para dramatizar a submissão feminina na sociedade" (MONTEIRO, 2004, p. 66).

Mesmo que, obviamente, o espaço do convento não seja o do texto cardosiano, é possível pensar tal locus em termos de representação não só pelas descrições do espaço, mas em nível temático e metafórico, já que o vampirismo da personagem apresenta estreita relação com a clausura da qual compartilha. As paredes de cor cinza, a ausência de janela, a porta gradeada como as de uma prisão e o fato do cômodo não se comunicar com outros da casa são características bastante sugestivas de um espaço à parte. É válido ressaltar também que, com a passagem para o século XIX, ocorre a transposição topográfica do gótico: dos castelos, abadias e conventos da tradição setecentista para a casa burguesa e a realidade urbana dos centros industrializados. Fred Botting, já no texto introdutório de seu estudo Gothic, considera que as paisagens, antes focadas em locais montanhosos e selvagens, são transmutadas para a cidade com suas ruas labirínticas e escuras, evocando a mesma sensação de violência e ameaça dos castelos e florestas góticos, reforçando a relação política e social do gótico, visto que "as 
GOMES, L.R.B.; , JUNIOR,F.B.M.

narrativas góticas nunca escaparam às preocupações de seus próprios tempos" (BOTTING, 1996, p. 2).

Gina é uma personagem caracterizada pela melancolia, aspecto também presente no pai de Mathilda. É na condição melancólica da mesma que surge a Mulher de Preto, personagem de caráter sobrenatural, com a qual Gina mantém relações desde a infância e se manifesta como duplo da personagem; a Mulher de Preto é quem inquire Gina a respeito do marido: "você tem medo do seu marido. Já se esqueceu da sua ridícula maneira de falar, das gravatas de mau gosto, da tesourinha com que corta meticulosamente as unhas... esqueceu todos esses horríveis hábitos que tanto detesta?" (CARDOSO, 2006, p. 171). A Mulher de Preto lhe instiga: "e você queria ser igual a todo mundo? Não desejava ter mãos fortes e cruéis, olhos frios e lábios capazes de mentir?" (CARDOSO, 2006, p. 171). Sozinha e sentada no divã, retoma a consciência do duplo da personagem, que admite para si mesma: "ela sou eu mesma, tenho certeza disto. Somos uma só e a mesma criatura, dissociadas, é verdade, porque houve uma ruptura em minha vida [...]" (CARDOSO, 2006, p. 177). A dissociação da personagem pode ser relacionada à estética da violência, como caracteriza Jaime Ginzburg:

violência e melancolia articulam o campo da estética em torno da perda, da dissociação e, muito frequentemente, da morte. [...] A estética da violência trabalha com o movimento tenso entre a vida e a morte, que admite recursos como a fragmentação, o grotesco o abjeto e o choque (GINZBURG, 2012, p. 28).

Se considerarmos a melancolia como "resultado de uma perda afetiva [...] envolvendo um afeto central para a vida do sujeito" (GINZBURG, 2012, p. 11), enquanto Gina experimenta uma dissociação consigo mesma, o pai de Mathilda experimenta a perda afetiva da esposa, a qual o coloca em posição de nômade e passivelmente voltado ao passado, tentando materializar na filha a amante perdida, o que acarreta em comportamentos dúbios e inquietos próprios de seu estado melancólico e inadaptação à realidade sem a amada:

o melancólico confronta-se com os limites da existência constantemente, pois associa sua perda à incerteza quanto à possibilidade de que qualquer coisa possa de fato fazer sentido. E um ponto central da condição melancólica consiste na atitude autodestrutiva. Impregnado de um amor que não pode ser correspondido e jogado em um campo de dor da perda, o sujeito agride a si mesmo (GINZBURG, 2012, p. 12).

A personagem feminina de Cardoso aproxima-se do pai de Mathilda principalmente no que tange ao arquétipo do vilão gótico. Talvez a característica que melhor evidencie este vínculo seja o olhar e humor de tais personagens, que se adequam 
GOMES, L.R.B.; , JUNIOR,F.B.M.

satisfatoriamente ao perfil de agente do Mal, que aparece como questão, possibilidade de expor paixões que demarcam fortemente tais personagens, "como se o Mal fosse o meio mais forte de expor a paixão" (BATAILLE, 1989, p. 14). Estes recortes também são expressos pela aderência a traços vampirescos. É Daniel Serravale de Sá quem ressalta: "o vilão geralmente tem algo de magnético ou perturbador" (SÁ, 2010, p. 78), além de ser comum "a intimidação na forma de olhos ou olhares temíveis" (SÁ, 2010, p. 84). A confluência de significados que envolve o antagonista engloba também "os desejos estranhos, a falta de controle, as motivações veladas, forças destrutivas etc" (SÁ, 2010, p.74). Sá também alerta a outra constante dos vilões, justamente de uma personalidade obsessiva e propensa a acessos de fúria (2010, p. 80), traço correspondido pelos dois personagens.

Ao indicarmos a correspondência de Gina ao vilão gótico almejamos muito mais constatar o texto dramático de Lúcio enquanto produção gótica do que endossar um estigma de mulher histérica que acompanhou diversas personagens femininas ao longo da história da literatura. Frente a um marido que deseja mantê-la subjugada a certos padrões, a opressão da casa, é a aderência a sua contraparte vampírica, manifesta no duplo da personagem, a Mulher de preto, que possibilita a Gina a rebelião ao que lhe é imposto. Lemos, portanto, a vampira como condição viável à transgressão da instituição que Ihe vitimiza, não pelo viés do doentio e do incômodo que coordena o olhar dos personagens masculinos sobre Gina - ainda que o vampiro tenda a ter representações negativas devido à desestabilização e perturbação da ordem.

O vampirismo é manifesto em cada enredo extremamente imbricado à sexualidade, vínculo estabelecido desde a tradição folclórica do vampiro e que corrobora adequadamente à corrosão da instituição familiar; já que esta sempre funcionou como reguladora da sexualidade, como bem apontado nas considerações do estudioso Christopher Lasch acerca da vida cotidiana e a mulher, o vampiro parece o arquétipo ideal para transgredir:

É impossível entender a história da família do século XIX a menos que vejamos o impulso para 'controlar a sexualidade', como ele [Degler] diz, como parte de uma campanha maior de controlar todo o resto - ou seja, examinar a sociedade ao microscópio. A intensificação emocional da vida familiar, em vez de gerar cooperação, provocou conflitos entre maridos e mulheres e pais e filhos. Estes conflitos desnudaram a atração sexual entre pai e filhos e as complicações decorrentes das relações entre homens e mulheres adultos. Os 'psiquiatras' do século XIX e os reformadores da área da saúde já percebiam a ligação entre a repressão sexual e a neurose [...] (LASCH, 1999, p. 184). 
GOMES, L.R.B.; , JUNIOR,F.B.M.

A atividade vampírica de Gina se dá após uma discussão na qual Renato tem ímpetos agressivos; não é explicitamente no pescoço, mostrando-se muito mais gradual, hipnótica, em um processo lento de dominação. Renato se vê esmaecido diante do hipnotismo da esposa. Tal momento talvez seja o que melhor evidencia o teor sexual de Gina que, voluptuosa, como destacado pela rubrica, declara:

Eu afagarei seus cabelos, devagar, bem devagar, até que a madrugada chegue. E seu rosto também, Renato, seu rosto pálido, assim, até o pescoço... até esse pescoço macio... esse pescoço lânguido onde o sangue bate delicado... e que parece ter sido feito para a carícia de uma corda (CARDOSO, 2006, p. 183).

Gina, nesses momentos, adquire contornos eróticos, tendo na sensualidade o caráter exacerbado da vampira, que vem desde a tradição folclórica (ARGEL E NETO, 2008, p. 23). Relembra-se também Lilith, que "é antes de tudo uma sedutora de homens" (PRAZ, 1996, p. 250), que representaria, portanto, um grande perigo. É Ginzburg ainda que considera o diálogo entre agressividade e erotismo:

o comportamento violento pode constituir um prazer, uma satisfação [...] o erotismo admite componentes destrutivos [...] existe prazer no movimento agressivo [...] agressividade e erotismo teriam em comum a capacidade de construir tensões e desequilibrar o estado habitual das relações do sujeito com o mundo externo (GINZBURG, 2012, p. 43).

Como constatado por Monteiro, "o espaço trancado define na narrativa a fronteira entre a repressão e a voracidade sexual, e as interferências nos espaços levam à tragédia" (MONTEIRO, 2004, p. 51). No ato final da discussão do casal a Mulher de Preto retorna e oferece a Gina uma corda de prata, "nova, forte, flexível, como se tivesse vida" (CARDOSO, 2006, p. 195), a qual Gina examina com admiração: "como é bonita! Sim, é de prata e parece ter vida! Olha como brilha e se agita!" (CARDOSO, 2006, p. 195). Após outro episódio de vampirização, Gina decreta: "que nenhuma batida do seu coração seja senão um reflexo do que bate em meu peito, que você só respire o ar que eu respire" (CARDOSO, 2006, p. 200), o que resgata muito da tradição vampírica tanto em exigência de um amor total como também a imagem do sangue, como do jovem rapaz de Corinto, da balada vampiresca de Goethe. É neste estado de torpor, com Renato já adormecido, que Gina, sugestionada pela Mulher de Preto, Ihe passa a corda pelo pescoço, "de pé, premindo o corpo com o joelho" (CARDOSO, 2006, p. 201), lutando "até que o corpo de Renato tomba de cabeça para baixo, meio fora do divã” (CARDOSO, 2006, p. 201). Gina contempla o cadáver "com ar sonâmbulo" (CARDOSO, 2006, p. 201) e logo é acusada pela Mulher de Preto: "você o matou, olhe bem para suas mãos" (CARDOSO, 2006, p. 201). 
GOMES, L.R.B.; , JUNIOR,F.B.M.

Gina se posiciona no centro da luz, do qual "a Mulher de Preto desaparece, enquanto a luz continua - e, nela, Gina sozinha" (CARDOSO, 2006, p. 203). Observando a cena, Júlia e o Dr. Vítor sussurram, afastados; ao ser questionado por Júlia se nada poderia salvar Gina, o médico arremata: "quem ousaria descer a este inferno? [...] Só Deus - se tiver pena de tão grande solidão" (CARDOSO, 2006, p. 204).

Cabe relembrar novamente Conceição Monteiro, que, citando Fred Botting, considera a consumação do espaço doméstico e a ameaça da desintegração social:

[na] ficção gótica o poder ilegítimo e a violência não só são expostos, mas também ameaçam consumir os valores do mundo doméstico civilizado. As tendências eróticas e incestuosas do vilão gótico expressam a sombra funesta da desintegração social em que a virtude dá lugar ao vício, a razão ao desejo e a lei à tirania (MONTEIRO, 2004, p. 107).

Já em Mathilda, o que altera violentamente o comportamento do pai é a percepção de homens cortejando Mathilda, desta sendo objeto de amor de outros; a partir disto, o mesmo revela: "foi então que o demônio despertou em mim [...] tudo era tumulto, crime, remorso e ódio... e, no entanto, o amor mais afetuoso" (SHELLEY, 2015, p. 79). O tratamento que direciona a filha, assim, é cruel, afastando-a muitas vezes, rejeitando-a, retendo o afeto que a filha, por fim, esperava, o que provoca nesta medo e uma intranquilidade que a acompanha dentro da própria casa: "o semblante carregado, os olhos presos ao chão em sombria fúria, e a voz, antes tão cara e gentil, fazia-me tremer quando a mim se dirigia" (SHELLEY, 2015, p. 43); "temendo não sabia o quê, mas sempre cheia de medo" (SHELLEY, 2015, p. 48).

A manifestação da paixão do pai se dá quando este convida Mathilda para a propriedade na qual passara a infância e onde a mãe residira quando criança, apresentando para a filha, inclusive, os quartos ocupados pela mãe, nos quais ainda residem os objetos que pertenceram a ela. É Mathilda quem o confronta acerca de seus sentimentos: "uma palavra!... exijo de ti a terrível palavra; ainda que seja um raio a destruir-me, fala" (SHELLEY, 2015, p. 62). Frente a tal insistência, o pai

pôs-se a responder com violência: 'sim, sim!... te odeio! Te odeio! És minha ruína, meu veneno, meu nojo! Ai de mim! Não! [...] fitando-me com um semblante que contorcia cada nervo e membro de meu corpo [...] 'minha filha, eu te amo! [...] talvez tenha me transformado como o anjo decaído. De fato creio ter me transformado, pois estou certo de ter uma nova alma dentro de mim, e meu sangue se agita em minhas veias... estou ardendo em febre (SHELLEY, 2015, p. 63).

Tal episódio é o mais sugestivo quanto ao caráter vampiresco do pai que, em meio a um bosque em penumbra, musgo, folhas mortas do outono e envolto pelo crepuscular, admite, por meio de gestos descontrolados, imagem de serpente: 
senti suas presas em meu coração; arranquei-me os cabelos; gritei; e, num momento de pena por seu sofrimento, quis tomar meu pai em meus braços; no entanto, caminhando para trás horrorizada, afastei-o com o pé cheia de repulsa; sentia-me como se tivesse sido picada por uma serpente, como se fosse fustigada pelo ferrão de escorpiões que me levavam.... (SHELLEY, 2015, p. 64).

O retorno de Mathilda para casa é traumático e já prefigura o isolamento e tristeza que dão o tom à personagem a partir deste episódio, agravado com o suicídio do pai, que Ihe deixa apenas uma carta. A personagem de Shelley volta 'quase morta' e impõe a si própria o autoexílio: "[...] tranquei-me em meu quarto [...] meu aposento ficava numa parte retirada da casa e confinava com o jardim, de modo que nenhum som dos demais habitantes o alcançava" (SHELLEY, 2015, p. 65, 66). De fato, o início da novela confirma a clausura que a partir daí será característica da personagem, já que tal começo se dá pelos dias anteriores à morte da personagem: "vivo numa cabana solitária, em ampla e afastada charneca - não há voz viva que me alcance [...] o frio há muito perdura. Meu estado mental é dos mais estranhos. Estou sozinha no mundo... muito sozinha... [...] sei que estou prestes a morrer e me sinto feliz.... é uma alegria” (SHELLEY, 2015, p. 11).

\section{CONSIDERAÇÕES FINAIS}

Os artifícios góticos narrativos, assim, parecem um trato adequado para dar conta das ameaças da ordem social e teriam tradução temática no que "parece dominar a ficção gótica: a natureza do poder, da lei, da sociedade, da família e da sexualidade" (VASCONCELOS apud MONTEIRO, 2004, p. 11). Porque a narrativa gótica é condicionada por aspectos sociais, um modo possível de expressão de temores sociais, medos que se mantinham no privado em um mundo em constante transformação, que oferece pouca estabilidade, sendo em sua própria constituição caótico e, pela adaptação a seu tempo, um movimento moderno:

o gótico tornou-se uma tradição artística que codificou, por meio de narrativas ficcionais, um modo de figurar os medos e expressar os interditos de uma sociedade [...] o que se chama de uma literatura gótica é, pois, a convergência entre uma percepção de mundo desencantada - com as cidades modernas, com o futuro que o progresso científico nos reserva, com o papel insignificante do homem no cosmos, com a própria natureza dessacralizada do homem (FRANÇA, 2017, p. 117).

A novela de Mary Shelley, de certo modo, não só expõe a dissolução da masculinidade e poder conferido culturalmente ao patriarca, como retrata a mesma intranquilidade na esfera privada, do doméstico enquanto espaço de perigo, contrariando o senso comum a respeito do casamento e constituição familiar, condição reservada, 
GOMES, L.R.B.; , JUNIOR,F.B.M.

sobretudo, às mulheres. No texto dramático de Lúcio Cardoso o crime no leito matrimonial atesta a instabilidade e o risco das relações próximas e afetivas, assim como a dissolução do casamento se dá pela agência da personagem feminina, em uma revolta direcionada ao espaço sobremaneira ofertado a mesma. Observamos também a recorrência de elementos góticos na produção brasileira, que mesmo temporalmente distanciada, apresenta marcas da tradição gótica inglesa. A opção de Shelley e de Cardoso no emprego de aspectos góticos na construção de suas produções promove ao leitor outra ótica à constituição das novas formas de organização social e familiar mantidas culturalmente, contribuindo para a concepção do gótico como um gênero de denúncia e contestação da ordem estabelecida e mantida e socialmente.

\section{REFERÊNCIAS}

ARGEL, Martha; NETO, Humberto Moura. O vampiro antes do Drácula. São Paulo: Aleph, 2008.

BATAILLE, Georges. A literatura e o mal. Trad. Suely Bastos. Porto Alegre: L\&PM, 1989.

BOTTING, Fred. Gothic. London/New York: Routledge, 1996.

CARDOSO, Lúcio. Teatro reunido. Curitiba: Ed. UFPR, 2006.

CHEVALIER, Jean. Dicionário de símbolos: (mitos, sonhos, costumes, gestos, formas, figuras, cores, números) / Jean Chevalier, Alain Gheerbrant, com a colaboração de: André Barbault... [et al]; coordenação Carlos Sussekind; trad. Vera da Costa e Silva... [et al]. 10a ed. Rio de Janeiro: José Olympio, 1996.

FRANÇA, Júlio. As nuances do gótico: do setecentos à atualidade. Rio de Janeiro: Bonecker, 2017.

GAY, Peter. A experiência burguesa da rainha Vitória a Freud: a educação dos sentidos. São Paulo: Companhia das Letras, 1988.

GINZBURG, Jaime. Literatura, violência e melancolia. Campinas, SP: Autores Associados, 2012 (Coleção ensaios e letras).

LASCH, Christopher. A mulher e a vida cotidiana: amor, casamento e feminismo. Rio de Janeiro: Civilização brasileira, 1999.

LECOUTEUX, Claude. História dos vampiros: autópsia de um mito. Trad. Álvaro Lorencini. São Paulo: Editora UNESP, 2005.

MONTEIRO, Maria Conceição. Na aurora da modernidade: a ascensão dos romances gótico e cortês na literatura inglesa. Rio de Janeiro: Caetés, 2004. 
GOMES, L.R.B.; , JUNIOR,F.B.M.

PRAZ, Mario. A carne, a morte e o diabo na literatura romântica. Trad. Philadelpho Meneses. Campinas: Editora UNICAMP, 1996.

SÁ, Daniel Serravalle de. Gótico tropical: o sublime e o demoníaco em O guarani. Salvador: EDUFBA, 2010.

SHELLEY, MARY. Mathilda. Trad. Bruno Gambarotto. São Paulo: Grua Livros, 2015.

STOKER. Bram. Drácula. Trad. Adriana Lisboa. Rio de Janeiro: Nova Fronteira, 2011.

VASCONCELOS, Sandra Guardini. Apresentação. IN: MONTEIRO, Maria Conceição. Na aurora da modernidade: a ascensão dos romances gótico e cortês na literatura inglesa. Rio de Janeiro: Caetés, 2004.

\section{Como citar este artigo (ABNT)}

GOMES, L.R.B.; JUNIOR, F.B.M. A Clausura Feminina Em A Corda De Prata, de Lúcio Cardoso, e Mathilda, de Mary Shelley. SELL, Uberaba, MG, v. X, n. X, p. XXX-XXX, 2019. Disponível em: <inserir link de acesso>. Acesso em: inserir dia, mês e ano de acesso. DOI: inserir link do DOI.

Como citar este artigo (APA)

Gomes, L.R.B. \& Junior, F.B.M. (2020). A Clausura Feminina Em A Corda De Prata, de Lúcio Cardoso, e Mathilda, de Mary Shelley. SELL, X (X), XXX-XXX. Recuperado em: inserir dia, mês e ano de acesso de inserir link de acesso. DOI: inserir link do DOI. 